\title{
Dynamic adsorption of volatile organic compounds on organofunctionalized SBA-15 materials
}

\author{
Qin $\mathrm{Hu}^{\mathrm{a}}$, Jin Jun $\mathrm{Li}^{\mathrm{a}}$, Zheng Ping Hao ${ }^{\mathrm{a}, *}$, Lan Dong $\mathrm{Li}^{\mathrm{a}}$, Shi Zhang Qiao ${ }^{\mathrm{b}}$ \\ a Department of Environmental Nano-Materials, Research Center for Eco-Environmental Sciences, Chinese Academy of Sciences, Beijing 100085, PR China \\ ${ }^{\mathrm{b}}$ ARC Centre for Functional Nanomaterials, School of Engineering and Australian Institute for Bioengineering and Nanotechnology, The University of Queensland, \\ Brisbane, QLD 4072, Australia
}

\section{A R T I C L E I N F O}

\section{Article history:}

Received 3 July 2008

Received in revised form 29 October 2008

Accepted 4 November 2008

\section{Keywords:}

Functionalized SBA-15

VOCs

Breakthrough curves

Mathematical model

Bicomponent adsorption

\begin{abstract}
A B S T R A C T
Organofunctionalized SBA-15 materials, including methyl-SBA-15 and phenyl-SBA-15, were synthesized by co-condensation method of tetraethyl orthosilicate (TEOS) and organosilanes such as methyltriethoxysilane (MTES) and phenyltriethoxysilane (PTES) under acidic conditions, and used as adsorbents for the VOCs abatement. These adsorbents were characterized by powder X-ray diffraction, $\mathrm{N}_{2}$ adsorption/desorption isotherms and FT-IR spectroscopy techniques. The results indicated that all samples showed a highly ordered two dimensional hexagonal mesostructure and the organic groups were chemically incorporated into the pore surface of SBA- 15 substrate. The dynamic adsorption behaviors of single VOC component (benzene) on methyl-SBA-15 and phenyl-SBA-15 adsorbents were evaluated via breakthrough curves. It was found that the adsorbent with the PTES/TEOS molar ratio at 1:10 had the largest capacity $\left(0.650 \mathrm{mmol} / \mathrm{g}_{\text {adsorbent }}\right)$ in the single component dynamic adsorption and the phenyl groups had stronger attractive interaction with benzene than the methyl groups. A mathematical model for the organofunctionalized SBA-15 adsorbents was successfully employed to describe the adsorption breakthrough curves of benzene. For binary component adsorption, the phenyl-SBA-15 exhibited the $\pi$ electrons effect between the adsorbate and the adsorbent, as the phenyl-SBA-15 materials preferred to adsorb benzene to cyclohexane. The larger dynamic VOCs capacity of the organofunctionalized SBA-15 materials was attributed to the synergetic effect between the amount of organic groups and the total pore volume.
\end{abstract}

(c) 2008 Elsevier B.V. All rights reserved.

\section{Introduction}

Emissions of volatile organic compounds (VOCs) are becoming one of the most stringent environmental challenges in many industrial processes. VOCs are known as one of the major contributors to the formation of photochemical ozone and secondary organic aerosol (SOA), which would result in harmfully healthy and seriously environmental problems. There are a number of technologies available for VOCs abatement, among which, sorption is a reliable chemical engineering method widely used because of the flexibility of the system, low energy and cheap operation costs [1-3]. Activated carbon is also the most widespread alternative to eliminate the volatile organic compounds due to its developed microporosity which ensures good adsorption capacities [4]. However, its application is limited by the sensibility to high temperature, difficult regeneration and shortcomings of pore blocking and hygroscopic-

\footnotetext{
* Corresponding author. Tel.: +86 10 62849194; fax: +861062923564.

E-mail address: zpinghao@rcees.ac.cn (Z.P. Hao).
}

ity [5]. Hence, different alternative adsorbents are desirable to be developed to overcome these kinds of problems.

Recently, a new ordered mesoporous silica family (MCM-41 [6], SBA-15 [7], HMS [8], etc.) was used as adsorbents for the VOCs removal. These ordered mesoporous materials show a large BET surface area, high porosity, controllable and narrowly distributed pore sizes and good mechanical stability that are greatly suitable in the adsorption of VOCs. The feasibility of tailoring their surface properties by introducing hydrophobic functional groups (such as methyl, phenyl and so on) into the special places of the silica framework makes them even more attractive in the adsorption and elimination of undesired compounds $[9,10]$. Especially, SBA-15 has large pore size to separate large VOCs molecules and high ther$\mathrm{mal} /$ hydrothermal stability due to the thickness of the silica walls. On the other hand, SBA-15 materials have complementary micropores in the silica walls connecting the primary one-dimensional mesopore channels to form a well-defined 2D hexagonal array. These SBA-type materials with bimodal pore distribution have been approved a high affinity for various VOCs due to their complementary micropores [7,11,12]. 
It is expected that the incorporation of organic groups into the framework of the mesoporous materials will modify their adsorptive properties by improving their affinity to organic compounds [13]. The incorporation of organic groups can be achieved in three ways as related paper summarized [9]: (1) by subsequent attachment of organic compounds onto a pure silica framework, i.e. grafting, (2) by simultaneous condensation reaction of inorganic silica species with silylated organic compounds, i.e. co-condensation, and (3) by using the bissilylated organic precursors that lead to periodic mesoporous organosilicas (PMOs). Especially for cocondensation, which involves copolymerization of organosilanes (such as methyltriethoxysilane and phenyltriethoxysilane) with a siloxane (such as tetraethyl orthosilicate) in the presence of a surfactant template, offers a higher and more uniform surface coverage of functional groups and a better control over the amount of the incorporated organosilanes. Therefore, in this work, the synthesis of functionalized SBA-15 was performed by co-condensation method.

Lots of works were reported on the wide applications of functionalized SBA-15 matetials. Nguyen et al. [14] synthesized functionalized SBA-15 via incorporating 3-aminopropylethoxysilane (APTES) on SBA-15 to separate protein effectively. Li et al. [15] investigated that functionalized SBA- 15 by aminopropyl, imidazole and triazole groups and found the excellent adsorption capacity for $\mathrm{Cr}(\mathrm{VI})$ and fast adsorption rate. However, rare studies about the VOCs adsorption on functionalized SBA-15 materials are available, especially the adsorptive studies on the SBA- 15 with different organosilanes/TEOS ratios and various VOCs components. In this sense, the development of functionalized mesoporous silicas for VOCs adsorption could generate a considerable interest.

This study focuses on the synthesis of SBA- 15 functionalized by methyl or phenyl groups with different organosilane/TEOS molar ratios using co-condensation method and used as adsorbents for VOCs abatement. The dynamic adsorption behaviors of single component benzene and bicomponent (benzene and cyclohexane) were investigated on these organofunctionalized SBA-15 materials. The aim of this study is to explore the affinity between VOCs pollutants and functionalized groups incorporated into the surface of SBA-15 substrate using the dynamic adsorption behaviors. And the adsorbents material property was studied by adjusting different molar ratios of MTES/TEOS and PTES/TEOS present in the initial synthesis mixtures on the formation of functionalized SBA15 , respectively.

\section{Experimental}

\subsection{Materials preparation}

Chemicals used in this study include tetraethyl orthosilicate (TEOS), pluronics P123 (MW: 5800, Aldrich), methyltriethoxysilane (MTES, 98+\%, Acros Organics), phenyltriethoxysilane (PTES, 98\%, Acros Organics), anhydrous ethanol (99.7\%) and fuming hydrochloric acid $(\mathrm{HCl}, 37 \%)$.

Pure SBA-15 and functionalized SBA-15 materials were synthesized by a method similar to Zhao et al. described [16]. The pure SBA-15 was prepared by TEOS as silica source and a nonionic triblock copolymer surfactant P123 as the structure-directing agent under acidic and hydrothermal conditions. The chemical composition of reaction mixture was 4g P123: 0.041 mol TEOS: $0.24 \mathrm{~mol}$ $\mathrm{HCl}$ : $6.67 \mathrm{~mol} \mathrm{H}_{2} \mathrm{O}$. Because of different hydrolysis ratios of TEOS and organosilanes, the synthesis of functionalized SBA-15 was similar to that of the pure SBA-15 sample except for an additional pre-hydrolyzed process as to get a much better defined mesostructure. Briefly, a certain molar ratio of organosilane (MTES or PTES) and TEOS (where the ratios of organosilane/TEOS were 1:20, 1:10,
$1: 5$, and $1: 15$ for PTES/TEOS only) was dissolved in $0.12 \mathrm{~mol} \mathrm{HCl}$ and $3.335 \mathrm{~mol} \mathrm{H}_{2} \mathrm{O}$ firstly, and then mixed with the surfactant solution (4 g P123: $0.12 \mathrm{~mol} \mathrm{HCl}: 3.335 \mathrm{~mol} \mathrm{H}_{2} \mathrm{O}$ ) to get a homogenous solution. Then, the mixtures were subjected to crystallization at $373 \mathrm{~K}$ for $48 \mathrm{~h}$ in Teflon bottles. All the crystallized products were centrifuged and washed by solution of $5 \mathrm{ml} \mathrm{HCl}(37 \%)$ in $250 \mathrm{ml}$ ethanol at $70^{\circ} \mathrm{C}$ for $6 \mathrm{~h}$ and repeated three times, then dried at $373 \mathrm{~K}$ overnight under vacuum condition.

\subsection{Materials characterization}

Small-angle X-ray diffraction (XRD) patterns were recorded on Siemens D5005 diffractometer at $40 \mathrm{kV}$ and $40 \mathrm{~mA}$ using a $\mathrm{Cu} \mathrm{K} \alpha$ radiation over the range $0.7^{\circ} \leq 2 \theta \leq 6.0^{\circ}$. Nitrogen adsorption/desorption isotherms were measured at liquid nitrogen temperature, using a NOVA1200 gas sorption analyzer. Before the measurements, the samples were degassed under vacuum at $378 \mathrm{~K}$ for $6 \mathrm{~h}$. The BET surface areas were calculated based on the linear part of the BET plot $\left(\left(P / P_{0}\right)=0.05-0.25\right)$. The total pore volumes were estimated according to nitrogen uptake at a relative pressure $\left(P / P_{0}\right)$ of ca. 0.99 . The pore size distribution was derived from the desorption branch of the $\mathrm{N}_{2}$ isotherms using Barrett-Joyner-Halenda (BJH) method [17]. Infrared spectra were recorded on a Bruker Tensor 27 using diffuse reflectance infrared Fourier transform spectroscopy (DRIFT) techniques, scanned from $4000 \mathrm{~cm}^{-1}$ to $500 \mathrm{~cm}^{-1}$.

\subsection{Dynamic adsorption of VOCs}

Firstly, the samples were crushed and sieved between 40 mesh and 60 mesh. About $100 \mathrm{mg}$ of pelletized sample was loaded in the absorption bed (U-type tube), and the samples were heated at $110^{\circ} \mathrm{C}$ for overnight under vacuum condition to remove the physically adsorbed water molecules and small organic impurities adsorbed in pores. The dynamic adsorption of VOCs was carried out on the experimental set-up (represented schematically in Fig. 1). Nitrogen was taken as carrier gas and adjusted to keep the total gas flow rate at $50 \mathrm{ml} / \mathrm{min}$. The adsorption capacity of samples was evaluated from breakthrough curves obtained at $20^{\circ} \mathrm{C}$ in a mixed gas flow of ca. 1000 ppm VOCs (such as benzene) when line 1 and line 2 were opened for a single component adsorption experiment. To investigate the affinity between benzene and phenyl group incorporated into the surface of the SBA-15, dynamic adsorption of bicomponent ( $500 \mathrm{ppm}$ for benzene and $500 \mathrm{ppm}$ for cyclohexane) was analyzed when all three lines were simultaneously opened to generate benzene-cyclohexane-nitrogen mixture. The temperature of the saturators was kept at $0{ }^{\circ} \mathrm{C}$ in water/ice bath to generate a constant VOCs partial pressure. The gas concentration of VOCs was adjusted by controlling the flow rate of carrier gas. VOCs concentrations of the inlet and outlet were analyzed by gas chromatography (GC).

The dynamic adsorption capacity $(q)$ of the adsorbents was calculated from the breakthrough curves according to the equations [18] as follows:

$q=\frac{F_{\mathrm{A}} t_{q}}{W}$

The time $t_{q}$ is estimated according to (Eq. (2)):

$t_{q}=\int\left(1-\frac{C_{\mathrm{A}}}{C_{0}}\right) d t-t_{\mathrm{D}}$

where $F_{\mathrm{A}}$ is the molar flow of VOC, $W$ is the amount of the adsorbent loaded in the adsorption bed (U-type tube), $C_{A}$ and $C_{0}$ are the outlet and inlet concentration of the stream through the fixed bed column, respectively, and $t_{\mathrm{D}}$ is the dead time of the system, which is 


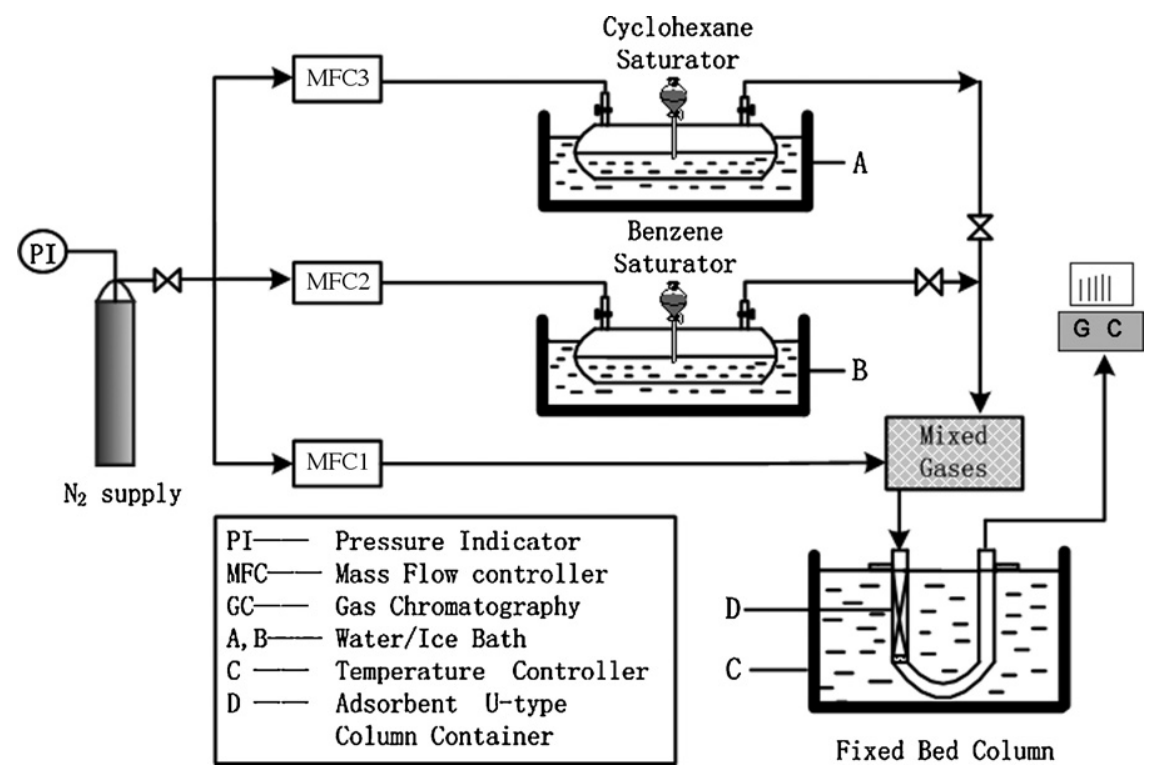

Fig. 1. Schematic diagram of experimental set-up.

a correction factor representing the time required by the adsorbate to travel from the saturator valve to the detector in the absence of adsorption phenomena.

\section{Results and discussion}

\subsection{Characterization of the adsorbents}

Figs. 2 and 3 show the XRD patterns of functionalized SBA15 together with pure SBA-15.The peaks indexed as (100), (110) and (200) in all the samples indicate well-defined SBA-15 mesostructure with two-dimensional hexagonal $p 6 \mathrm{~mm}$ symmetry. All samples exhibit a sharp peak indexed as $\left(\begin{array}{ll}10 & 0\end{array}\right)$, but the intensities of the functionalized SBA-15 materials are considerably lower and the peak positions are shifted to higher $2 \theta$ value compared to the pure SBA-15, which is consistent with Zhao's result [19]. Increasing the amount of organosilane added in the initial synthesis mixtures caused a decrease in $(110)$ and $(200)$ peaks remarkably, especially when the ratios reached 1:5 for MTES/TEOS and 1:10

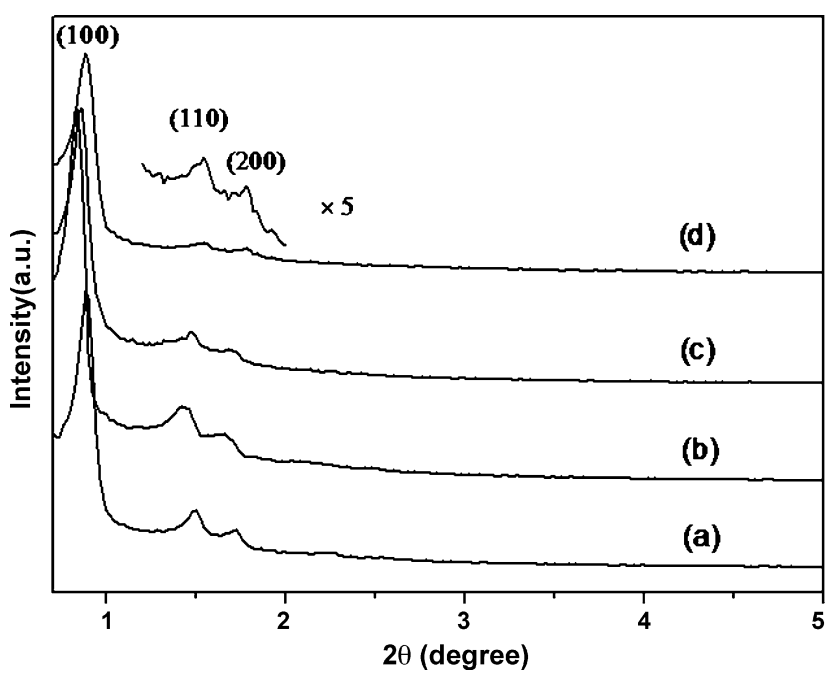

Fig. 2. XRD patterns of methyl-SBA-15 with different MTES/TEOS molar ratios: (a) pure SBA-15, (b) MTES/TEOS = 1:20, (c) MTES/TEOS = 1:10, and (d) MTES/TEOS = 1:5. for PTES/TEOS, respectively. However, the incorporation of MTES or PTES into the initial mixtures does not considerably disrupt the long-range mesoscopic order except a slight local disorder for the samples with larger concentrations of organosilanes, which is similar to the Wei's results [20].

Figs. 4 and 5 show the $\mathrm{N}_{2}$ adsorption-desorption isotherms and the pore size distribution (PSD) curves for the pure SBA-15 and functionalized SBA-15 materials. All samples exhibit type IV isotherms with type $\mathrm{H} 1$ hysteresis loops according to the IUPAC nomenclature, typical of mesoporous materials with 1D cylindrical channel [21]. However, ill-defined isotherms are observed when the PTES/TEOS reaches 1:5. As shown in Figs. 4(A) and 5(A), a position shift of the capillary condensation toward lower relative pressures occurs with the increase of the molar ratios for organosilanes/TEOS, which indicates the decrease of the mesopore size [22], and also confirmed by Fig. 4(B) and Fig. 5(B). The nitrogen isotherms exhibit that the amount of organosilanes present in the co-condensation synthesis process has a profound effect on the formation of SBA-15 mesostructures. Physicochemical properties of functionalized SBA-

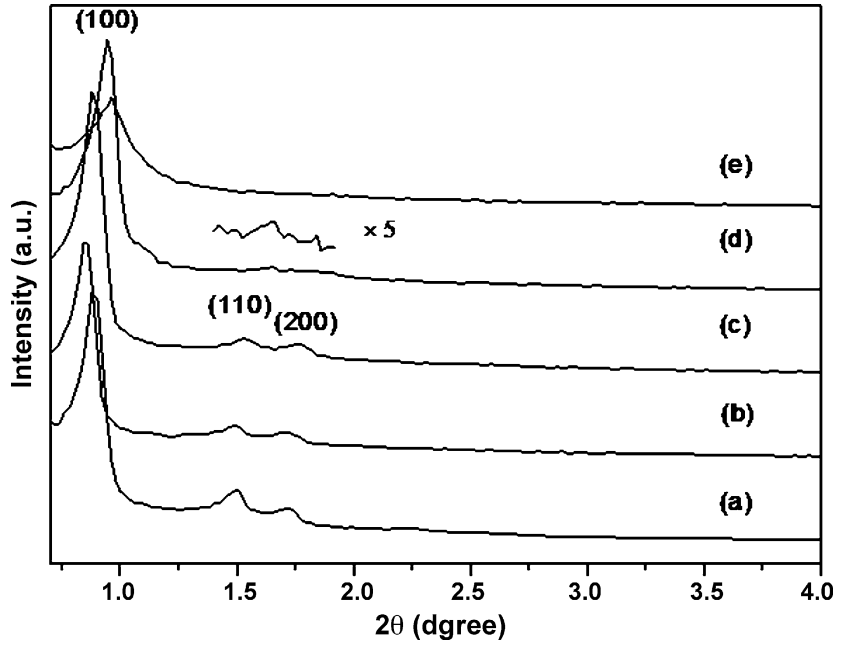

Fig. 3. XRD patterns of phenyl-SBA-15 with different PTES/TEOS molar ratios: (a) pure SBA-15; (b) PTES/TEOS=1:20; (c) PTES/TEOS=1:15; (d) PTES/TEOS=1:10; (e) $\mathrm{PTES} / \mathrm{TEOS}=1: 5$ 

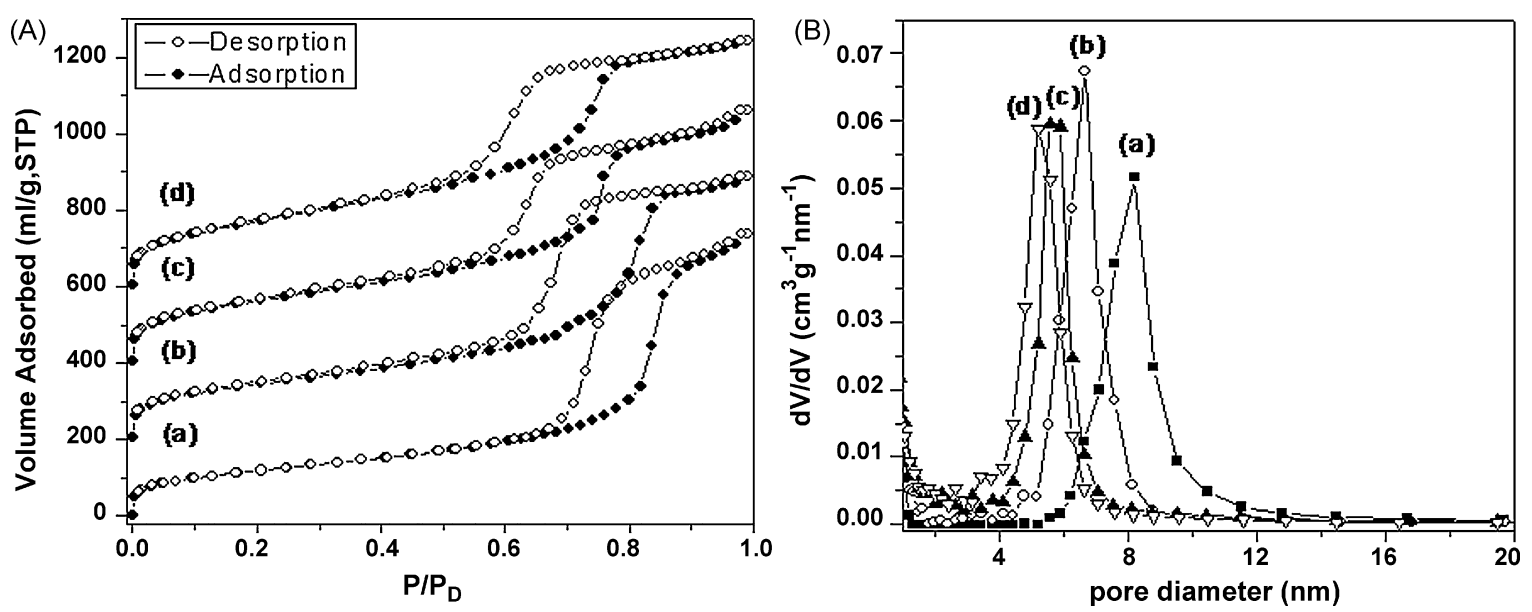

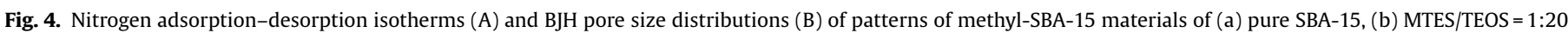
(c) $\mathrm{MTES} / \mathrm{TEOS}=1: 10$, and (d) MTES/TEOS $=1: 5$.
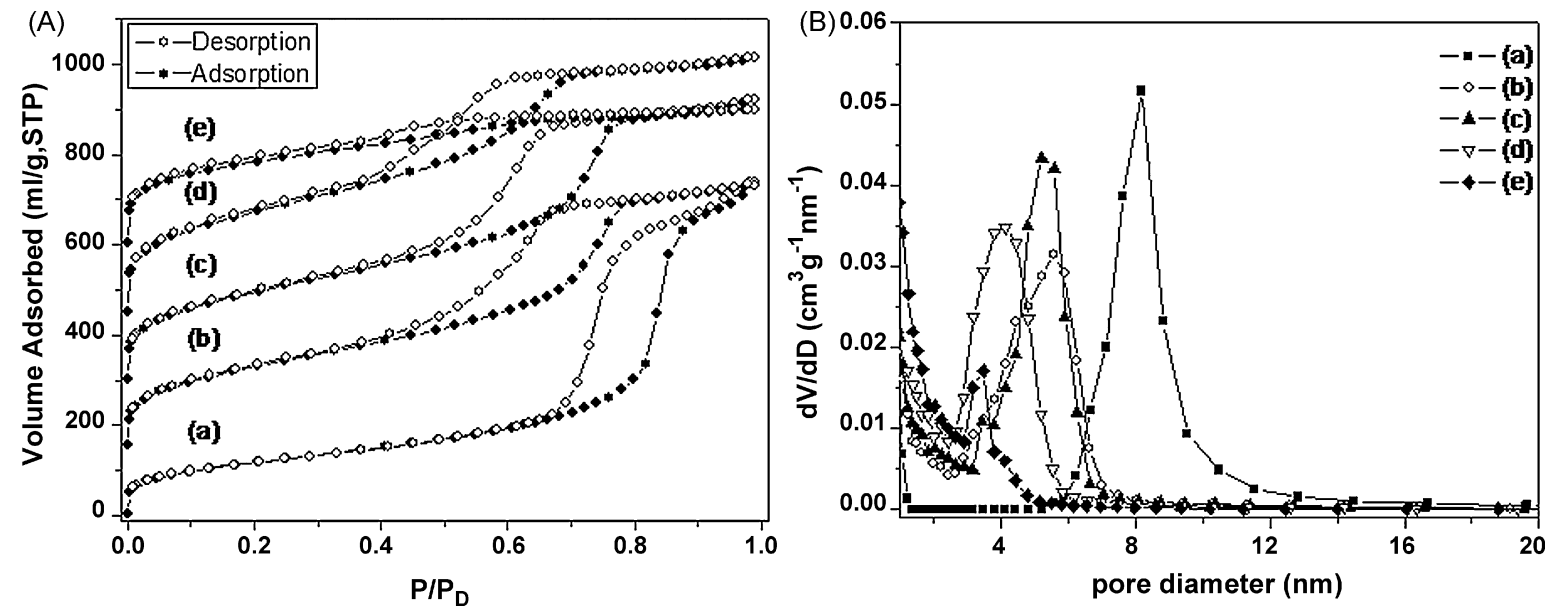

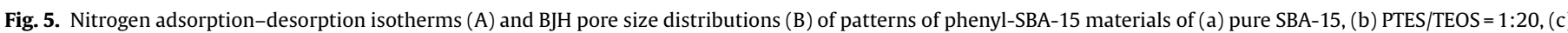
PTES/TEOS = 1:15, (d) PTES/TEOS = 1:10, and (e) PTES/TEOS = 1:5.

15 materials with different organosilanes/TEOS molar ratios are listed in Table 1. It is seen that with the increase of the molar ratios for organosilanes/TEOS, the total pore volume and BJH pore diameter of the samples decreased while the BET surface areas increased (except for 1:5 PTES) compared to the pure SBA-15. Very weak disruptive effect of MTES and PTES on SBA-15 mesostructure should mainly account for this observation, as mentioned by Chong et al. [23] that the incorporated VTES (vinyltriethoxysilane) on SBA-15 also has a very weak disruptive effect to the mesostructure.

The incorporation of methyl and phenyl groups in the SBA-15 frameworks can be qualitatively confirmed by the Fourier transform infrared (FTIR) spectra in Figs. 6 and 7, respectively. In Fig. 6, the peaks located at $1275 \mathrm{~cm}^{-1}$ and $2981 \mathrm{~cm}^{-1}$ assign to the vibration of the $\mathrm{Si}-\mathrm{C}$ bond and the $\mathrm{CH}_{3}$ unit, respectively [24], whose intensity increases with the raise of the molar ratios for MTES/TEOS, which is the evidence that methyl groups are incorporated into SBA-15 framework. The same trend of result was observed in Fig. 7 with the signals of phenyl groups. The peaks at $3055 \mathrm{~cm}^{-1}$ and $3076 \mathrm{~cm}^{-1}$ are attributed to the $\mathrm{C}-\mathrm{H}$ stretching vibrations of the phenyl groups, while the peaks at $1431 \mathrm{~cm}^{-1}$ and $1484 \mathrm{~cm}^{-1}$ are attributed to the $\mathrm{C}=\mathrm{C}$ vibration of the aromatic ring [25], and the peaks at $739 \mathrm{~cm}^{-1}$ and $698 \mathrm{~cm}^{-1}$ assign to the distinctive marks of benzene. The intensity of the peaks at $1350 \mathrm{~cm}^{-1}$ and $1379 \mathrm{~cm}^{-1}$ in both Figs. 6 and 7 due to the P123 surfactant residues is very weak,

Table 1

Porous properties and simulated parameters of organofunctionalized SBA-15 materials.

\begin{tabular}{|c|c|c|c|c|c|c|}
\hline Sample & BET surface area $\left(\mathrm{m}^{2} \mathrm{~g}^{-1}\right)$ & Pore diameter $(\mathrm{nm})$ & Total pore volume $\left(\mathrm{cm}^{3} \mathrm{~g}^{-1}\right)$ & $\tau_{0}(\min )$ & $k^{\prime}\left(\min ^{-1}\right)$ & $R^{2 \mathrm{a}}$ \\
\hline Pure SBA-15 & 501.0 & 8.15 & 1.143 & 28.45 & 0.206 & 0.991 \\
\hline (1:20)MTES & 512.0 & 6.67 & 1.068 & 30.43 & 0.153 & 0.983 \\
\hline (1:10)MTES & 577.1 & 5.57 & 1.027 & 51.85 & 0.130 & 0.986 \\
\hline (1:5)MTES & 611.4 & 5.20 & 0.994 & 27.84 & 0.152 & 0.976 \\
\hline (1:20)PTES & 637.5 & 5.57 & 0.903 & 47.53 & 0.156 & 0.988 \\
\hline (1:15)PTES & 692.4 & 5.20 & 0.963 & 62.16 & 0.212 & 0.996 \\
\hline (l:10)PTES & 794.5 & 4.41 & 0.873 & 67.59 & 0.106 & 0.989 \\
\hline (1:5)PTES & 645.6 & 3.44 & 0.465 & 64.06 & 0.166 & 0.995 \\
\hline
\end{tabular}

${ }^{\text {a }} R^{2}$ is the coefficient of determination. 


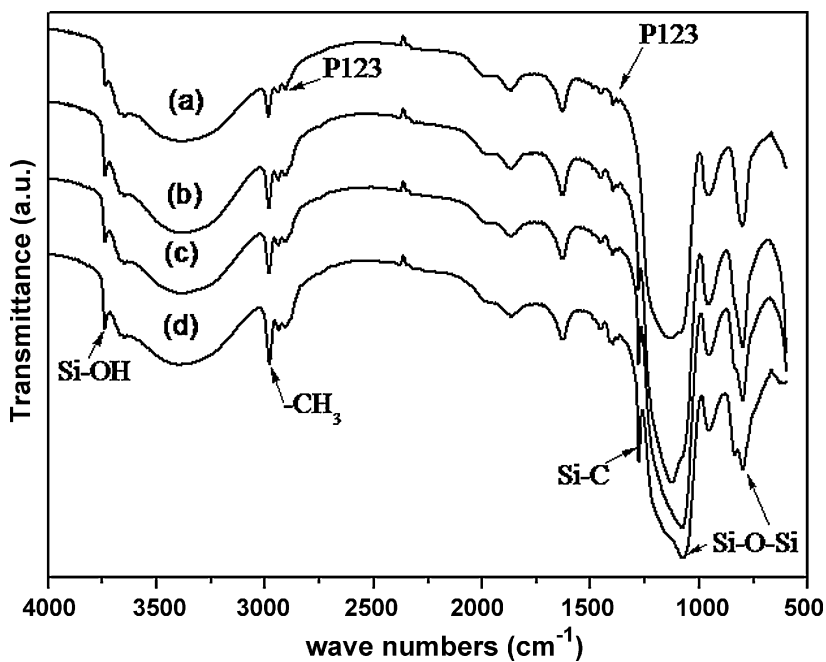

Fig. 6. FTIR spectra of patterns of methyl-SBA-15 materials of (a) pure SBA-15, (b) MTES/TEOS $=1: 20$, (c) MTES/TEOS $=1: 10$, and (d) MTES/TEOS $=1: 5$

suggesting the relatively effective removal of the surfactant by the solvent extraction method. Thus, the functional groups were chemically incorporated into the frameworks of ordered mesoporous materials by the co-condensation method.

\subsection{Dynamic adsorption of single component on the adsorbents}

A breakthrough measurement is a direct method designed to clarify the dynamic performance of VOCs adsorption at low concentration. The dynamic adsorption behavior of benzene was evaluated on these functionalized SBA-15 samples. In general, the longer the breakthrough time, the higher the dynamic adsorption capacity. Figs. 8 and 9 show the benzene breakthrough curves on methyl functionalized SBA-15 and phenyl functionalized SBA-15 adsorbents, respectively. The typical breakthrough curves give the evolution of the $C_{\mathrm{A}} / C_{0}$ ratio as a function of time, where $C_{\mathrm{A}}$ is the concentration of benzene at the outlet of the adsorption bed and $C_{0}$ is the concentration of benzene at the inlet [2].

Among the adsorbents employed in the present investigation, methyl-SBA-15 adsorbent with 1:10 ratio of MTES/TEOS and phenyl-SBA-15 adsorbent also with 1:10 ratio of PTES/TEOS exhibit

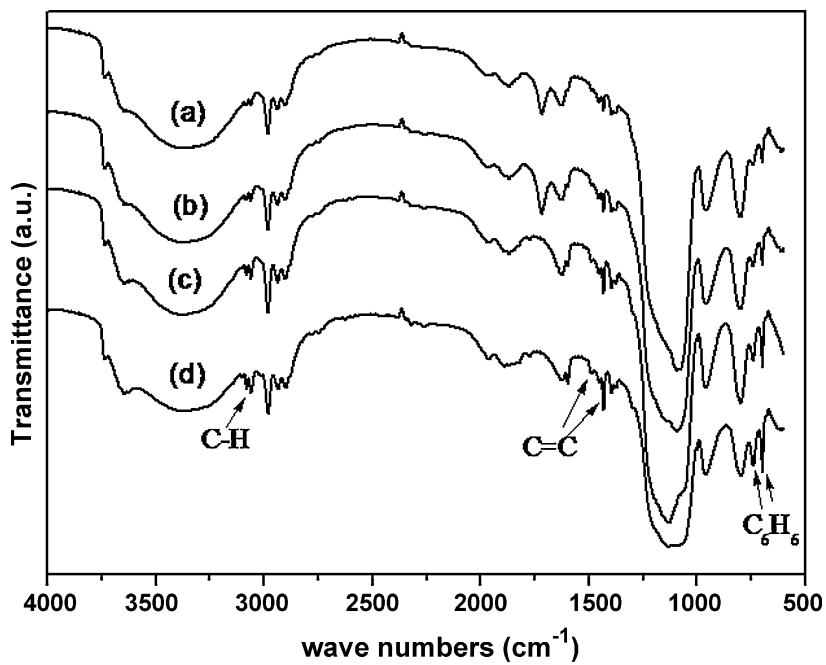

Fig. 7. FTIR spectra of patterns of phenyl-SBA-15 materials of (a) PTES/TEOS $=1: 20$; (b) PTES/TEOS = 1:15; (c) PTES/TEOS = 1:10; (d) PTES/TEOS = 1:5

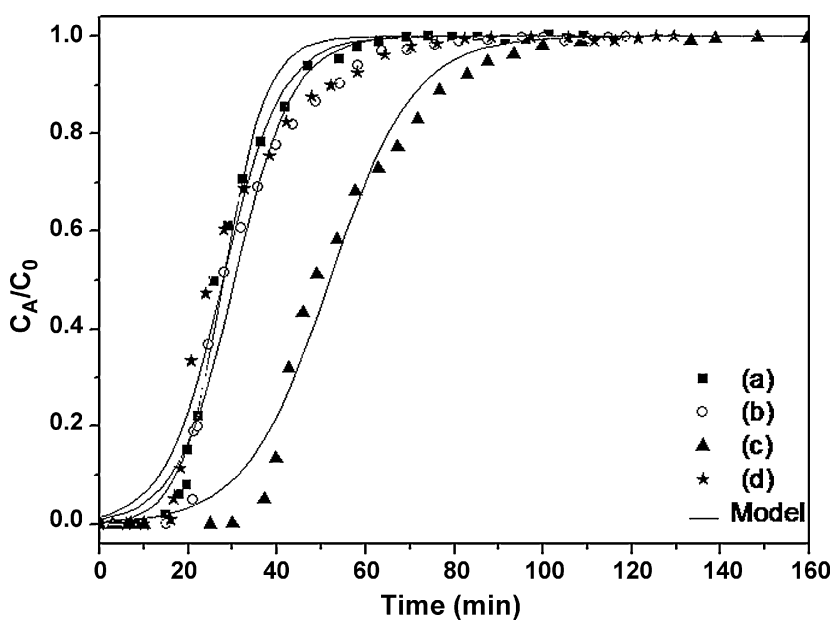

Fig. 8. The breakthrough curves and mathematic models for pure SBA-15 and methyl-SBA-15 materials of (a) pure SBA-15, (b) MTES/TEOS=1:20, (c) MTES/TEOS $=1: 10$, and $(\mathrm{d}) \mathrm{MTES} / \mathrm{TEOS}=1: 5$.

exceptionally good breakthrough curves and the highest adsorption capacity in the methyl-SBA-15 and phenyl-SBA-15 patterns, respectively. But further elevation in the ratios of organosilanes/TEOS cannot induce higher capacity. The physical properties were summarized in Table 1 . The functionalized SBA-15 samples with higher ratio of organosilane/TEOS have larger BET surface area and more organic groups in the surfaces (exhibited in FTIR spectra) which can improve their affinity to organic compounds such as benzene and obtain higher capacity. On the other hand, higher ratio of organosilanes/TEOS leads to lower total pore volume which otherwise makes the adsorption capacity decreased. It can be assumed that both the organic groups on the adsorbent surfaces and the total pore volume of the adsorbents can decide the adsorption capacity. And it must be noted that the dynamic benzene adsorption capacities are not linear with respect to the total pore volumes, as listed in Tables 1 and 2. Since the total pore volume decreased as the number of organic groups increased, there exists a highest dynamic adsorption capacity with respect to the optimal molar ratio of the functionalized SBA-15 adsorbents.

From Table 1, the pure SBA-15 adsorbent has the largest total pore volume $\left(1.143 \mathrm{~cm}^{3} \mathrm{~g}^{-1}\right)$, but it has a lower dynamic adsorp-

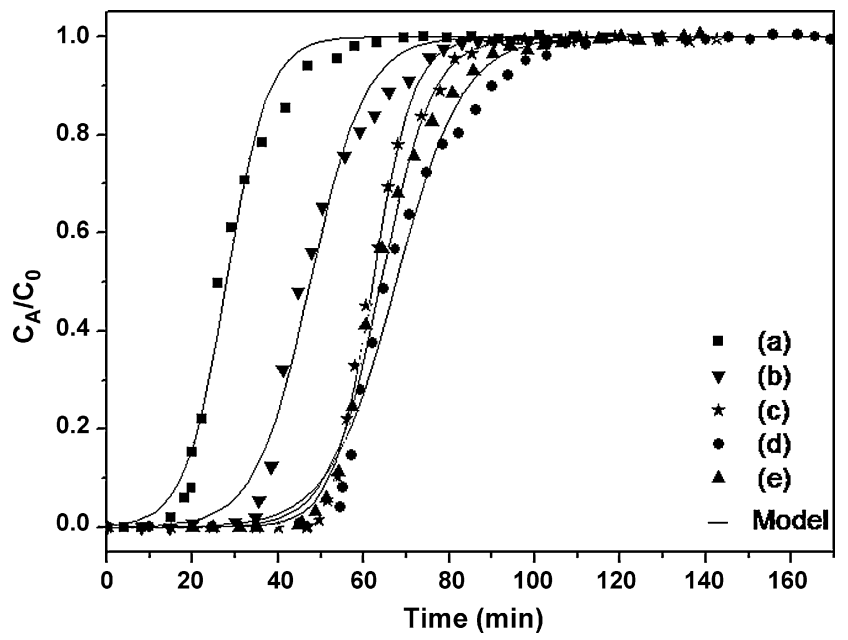

Fig. 9. The breakthrough curves and mathematic models for pure SBA-15 and phenyl-SBA-15 materials of (a) pure SBA-15; (b) PTES/TEOS=1:20; (c) PTES/TEOS = 1:15; (d) PTES/TEOS = 1:10; (e) PTES/TEOS = 1:5. 
Table 2

Dynamic adsorption capacity of the pure SBA-15 and functionalized SBA-15 adsorbents.

\begin{tabular}{|c|c|c|c|c|}
\hline \multirow[t]{3}{*}{ Adsorbents } & \multicolumn{4}{|c|}{ Dynamic adsorption capacity ( $\mathrm{mmol} / \mathrm{g}_{\text {adsorbent }}$ ) } \\
\hline & \multirow{2}{*}{$\begin{array}{l}\text { Single component } \\
\text { (benzene) }\end{array}$} & \multicolumn{3}{|l|}{ Bi component } \\
\hline & & Cyclohexane & Benzene & Total VOCs \\
\hline Pure SBA-15 & 0.292 & 0.160 & 0.340 & 0.500 \\
\hline (1:20)MTES & 0.360 & - & - & - \\
\hline (1:10)MTES & 0.418 & - & - & - \\
\hline (1:5)MTES & 0.283 & - & - & - \\
\hline (1:20)PTES & 0.478 & 0.189 & 0.419 & 0.608 \\
\hline (1:15)PTES & 0.632 & 0.330 & 0.524 & 0.854 \\
\hline (1:10)PTES & 0.650 & 0.285 & 0.449 & 0.734 \\
\hline (1:5)PTES & 0.626 & 0.193 & 0.433 & 0.626 \\
\hline
\end{tabular}

tion capacity $\left(0.292 \mathrm{mmol} / \mathrm{g}_{\text {adsorbent }}\right.$ in Table 2$)$ which is agreement with the result of the Kosuge's et al. work that showed adsorbents with a larger volumetric capacity do not necessarily have a larger breakthrough capacity [11]. Due to lots of $\mathrm{Si}-\mathrm{OH}$ groups on the surfaces of pure SBA-15 adsorbent which promising the polar surface properties, it has a relatively lower adsorption capacity for benzene which is a non-polar molecule than that of the functionalized SBA15 adsorbents, the same result obtained in Zhao's et al. study that polar organics have a higher affinity to MCM-41 than to silicalite-1, while non-polar organics have a higher affinity to silicalite- 1 than to MCM-41 due to the difference between their strength of surface hydrophobicity and the difference between their pore structures [26].

It is expected that the incorporation of organic groups into the framework of the mesoporous materials could improve their affinity to organic compounds and modify their adsorptive properties. As shown in Table 2, the role of the surface chemistry of mesoporous materials with the functionalized groups is an important point in the adsorption process. The functionalized SBA-15 adsorbents with organic groups become more affinity to the organic compounds and generally have a larger adsorption capacity under the experimental conditions in this study, which is not consistent with the other's result that diffusion resistance and pore configuration posed by attachment of TMS (trimethylsilyl) groups are the key parameters in controlling the pore-filling process of benzene, rather than the surface chemistry [19]. In addition, the adsorbent with the MTES/TEOS ratio at 1:5 has a lower adsorption capacity than that of pure SBA-15 in Table 2. Though (1:5) MTES sample has relatively larger organic groups (methyl group) in the framework of mesoporous material to modify the surface property, the decrease of total pore volume neutralizes the advantage of getting a higher adsorption capacity.

The dynamic adsorption capacities for benzene on the adsorbents summarized in Table 2 show that phenyl-SBA- 15 adsorbents have much higher capacities than that of methyl-SBA-15 adsorbents. As Zhao's work shown, the silanol groups ( $\equiv \mathrm{Si}-\mathrm{OH})$ on the pore surfaces of silica-based adsorbents act as the adsorption sites for various molecules [26]. The same conclusion is obtained that the hydroxyl groups present in the silica surface behave as weak acid sites interacting strongly with the $\pi$-electrons of unsaturated organic molecules, such as benzene molecules [18]. However, in this study, the strong interaction between benzene and the phenyl groups on the surface of phenyl-SBA-15 adsorbents might explain the phenomenon that phenyl-SBA-15 adsorbents have higher capacities than methyl-SBA-15 and pure SBA-15 adsorbents. The dynamic benzene adsorption by functionalized SBA-15 samples might occur through $\pi$-system interaction between aromatic rings of benzene and functional groups (methyl or phenyl groups) on the SBA-15 surface [12]. And the phenyl groups have stronger attractive interaction with benzene than the methyl groups during the dynamic adsorption process. Therefore, the phenyl-SBA-15 adsorbents have higher affinity to the benzene than the methyl-SBA-15 adsorbents.

\subsection{Modeling of benzene adsorption on methyl-SBA-15 and phenyl-SBA-15 adsorbents}

To model benzene adsorption on these organofunctionalized materials, a mathematic model proposed by Yoon and Nelson [27] was used to simulate the breakthrough curves according to the following (Eq. (3)):

$\frac{C_{\mathrm{A}}}{C_{0}}=\frac{1}{1+\exp \left[k^{\prime}\left(\tau_{0}-t\right)\right]}$

where $C_{\mathrm{A}}$ and $C_{0}$ are the outlet and inlet concentration of the stream through the fixed bed column. $\tau_{0}$ is the stoichiometric time (time for $C_{\mathrm{A}}=0.5 C_{0}$ ), and $k^{\prime}$ is a constant that depends on the diffusion characteristics of the mass transfer zone. It is a simple model and can simulate the breakthrough curves well, as already used for modeling adsorption of volatile alcohols in the fixed bed of zeolite 13X [28], modeling adsorption of methyethylketone and benzene vapors in activated carbon fiber beds [29] and o-xylene onto bentonite clay and alumina [30] and so forth.

Regression analysis derived from (Eq. (3)) of the experimental breakthrough data obtained for benzene adsorption on methylSBA-15 (Fig. 8) and phenyl-SBA-15 (Fig. 9) adsorbents gave good agreement with the breakthrough curves, where two parameters of $\tau_{0}$ and $k^{\prime}$ and the relative coefficients $R^{2}$ are listed in Table 1 . The phenyl-SBA-15 adsorbent with PTES/TEOS ratio at $1: 10$ has the lowest $k^{\prime}$ value $\left(0.106 \mathrm{~min}^{-1}\right)$ and the largest $\tau_{0}$ value $(67.59 \mathrm{~min})$, being consistent with its highest dynamic adsorption capacity ( $\left.0.650 \mathrm{mmol} / \mathrm{g}_{\text {adsorbent }}\right)$ for benzene.

\subsection{Bicomponent adsorption on phenyl-SBA-15 adsorbents}

In order to further study the $\pi$-electrons effect between adsorbent and adsorbate in the dynamic adsorption process, bicomponent adsorption of cyclohexane and benzene was investigated via breakthrough experiments. Considered the lower dynamic adsorption capacities of the methyl-SBA-15 patterns compared to the phenyl-SBA- 15 patterns, the latter were only chosen for the bicomponent adsorption, as shown in Fig. 10. The cyclohex-

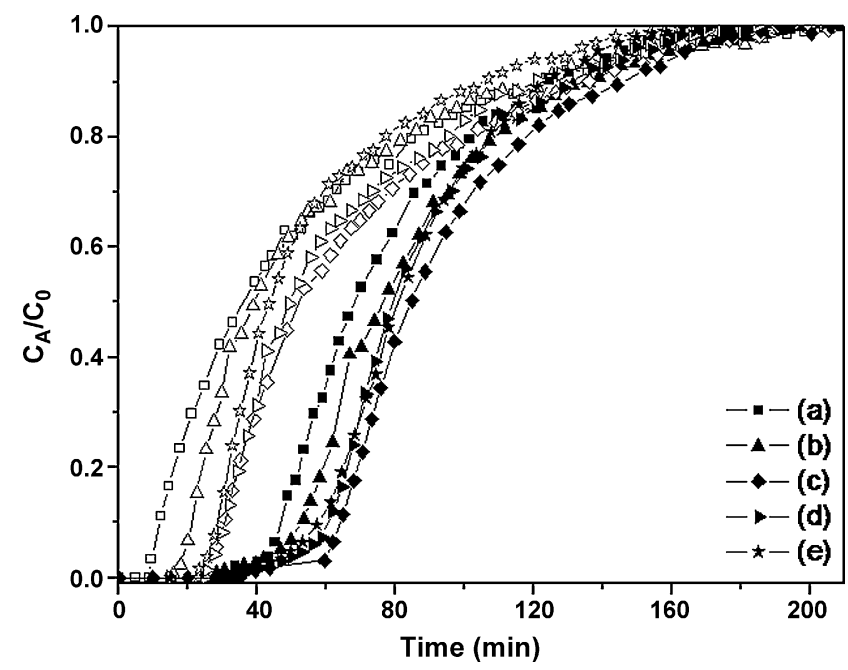

Fig. 10. Breakthrough profiles of cyclohexane (open) and benzene (filled) mix ture for pure SBA-15 and phenyl-SBA-15 adsorbents of (a) pure SBA-15; (b) PTES/TEOS = 1:20; (c) PTES/TEOS = 1:15; (d) PTES/TEOS =1:10; (e) PTES/TEOS = 1:5. 


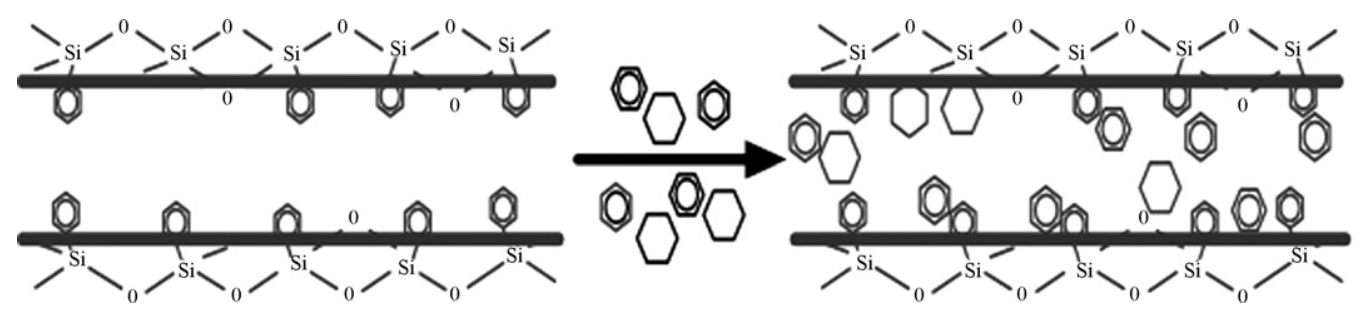

Fig. 11. Schematic representation showing the dynamic VOCs adsorption process of phenyl-SBA- 15 adsorbents.

ane, which is less polar than benzene, has the same carbon atoms and a cyclic structure as benzene. However, as shown in Fig. 10 and in Table 2, the values of the dynamic adsorption capacities for cyclohexane are much lower than those for benzene on pure SBA15 and phenyl-SBA-15 adsorbents. As the phenyl-SBA-15 samples have phenyl groups chemically incorporated into the surfaces of the framework, they have a more affinity for benzene molecules which also have $\pi$-electrons structure. Through the $\pi$-electrons interactions between adsorbate and adsorbent, the phenyl-SBA15 samples get a relatively higher benzene capacity compared to cyclohexane. Because the cyclohexane has a cyclic structure with a saturated cycloalkane, it naturally has a weak interaction with phenyl-SBA-15 adsorbents and hereby results in a lower adsorption capacity.

Both pure SBA-15 and phenyl-SBA-15 adsorbents show a relatively higher capacity for benzene than for cyclohexane, which is consistent with the longer breakthrough time of benzene compared to cyclohexane. In another word, the pure SBA-15 and phenyl-SBA15 adsorbents selectively adsorb benzene with an unsaturated ring rather than cyclohexane with a saturated ring, which is accordant with Newdlkar's et al. observation [31]. The adsorption capacities for cyclohexane, benzene and total VOCs increase with the raising molar ratio of PTES/TEOS up to $1: 15$. Schematic representation in Fig. 11 shows the dynamic bicomponent adsorption process on phenyl-SBA-15 adsorbents. It is assumed that benzene and cyclohexane molecules are trapped in the places due to the interaction of $\pi$-electrons effect, where benzene molecules are inclined to assemble around the phenyl groups on the surface channel of the functionalized SBA-15 adsorbents while the cyclohexane in the other gaps with a relatively weak $\pi$-electrons effect. However, the total VOCs adsorption capacity in the bicomponent dynamic adsorption process in Table 2 increased compared with adsorption of single component.

\subsection{Effect of surface property and pore structure on dynamic VOCs adsorption}

The incorporation of methyl and phenyl groups into the SBA-15 framework can obtain from modification in the surface property and the pore structure of the silica material. On the one hand, organic groups on the surface of the channel create adsorptive sites, which are affinitive to VOCs. On the other hand, too much organic groups decrease the total pore volume of the SBA-15 type adsorbents, which otherwise make against the VOCs adsorption. The functionalized SBA-15 sample with the molar ratio of PTES/TEOS at 1:10 has the highest capacity of benzene adsorption in the single component adsorption as shown in Table 2, while the functionalized SBA-15 sample with the molar ratio of PTES/TEOS at 1:15 possesses the highest capacity of VOCs adsorption during the binary components adsorption. The obtained results indicate that the adsorbate-adsorbent interaction between benzene and the functionalized SBA-15 adsorbents occurred. As suggested above, there may exist strong interaction of $\pi$-electrons effect between the functionalized phenyl-SBA-15 materials and the adsorbate of benzene.
Though the reduction in the total pore volume would make the adsorption capacity decreased, it is proved that the adsorption capacity for aromatic compounds is also strongly influenced by the surface property of the functionalized SBA-15 adsorbents. It is assumed that the control the molar ratio of organic groups in the initial synthesis can obtain a satisfactory adsorption capacity for the VOCs abatement. Therefore, it was pointed out that the larger dynamic VOCs adsorption capacity of the functionalized SBA-15 sample is derived from a synergetic effect between the amount of organic groups and the pore structure of adsorbents.

\section{Conclusions}

The dynamic adsorption of VOCs behaviors of single component and bicomponent adsorption were investigated via breakthrough experiment on the pure SBA-15, and the functionalized SBA-15 materials synthesized by co-condensation method. It is concluded that the functionalized SBA-15 materials are promising potential adsorbents for the VOCs abatement in low concentration. Proper modification of the surface properties of the SBA-15 substrate can significantly enhance the adsorption capacity. The high adsorption capacity and affinity to unsaturated VOCs benzene show the potential of the functionalized SBA-15 materials as suitable adsorbents for this kind VOC removal. Mathematic model of the experimental breakthrough data obtained for benzene adsorption on organofunctionalized SBA-15 adsorbents gave good agreement with the breakthrough curves. The phenyl-SBA-15 adsorbent with PTES/TEOS ratio at $1: 10$ has the lowest $k^{\prime}$ value $\left(0.106 \mathrm{~min}^{-1}\right)$ and the largest $\tau_{0}$ value $(67.59 \mathrm{~min})$, being consistent with its highest dynamic adsorption capacity $\left(0.650 \mathrm{mmol} / \mathrm{g}_{\text {adsorbent }}\right)$ for benzene. The bicomponent adsorption study demonstrated that $\pi$-electrons effect might play an important role in the dynamic adsorption, where the adsorbents showed a relatively higher capacity for benzene than cyclohexane. In this study, an optimal molar ratio of PTES/TEOS could produce highest adsorption capacity of VOCs, while increasing or decreasing the molar ratio of organosilane/TEOS further would reduce the dynamic adsorption capacity. It was revealed that the adsorption capacity was mainly influenced by the adsorption affinity and the total pore volume, this synergetic effect make the functionalized SBA-15 materials to be good candidates for the application in the reduction of industrial VOCs emissions.

\section{Acknowledgements}

This work was financially supported by the National Natural Science Foundation of China (20725723, 20877088 and 20807050) and National High Technology Research and Development Program of China (2006AA06A310).

\section{References}

[1] D.P. Serrano, G. Calleja, J.A. Botas, F.J. Gutierrez, Adsorption and hydrophobic properties of mesostructured MCM-41 and SBA-15 materials for volatile organic compound removal, Ind. Eng. Chem. Res. 43 (2004) 7010-7018. 
[2] M. Guillemot, J. Mijoin, S. Mignard, P. Magnoux, Adsorption of tetrachloroethylene on cationic $X$ and $Y$ zeolites: influence of cation nature and of water vapor Ind. Eng. Chem. Res. 46 (2007) 4614-4620.

[3] X. Hu, S. Qiao, X. Zhao, G. Lu, Adsorption study of benzene in ink-bottle-like MCM-41, Ind. Eng. Chem. Res. 40 (2001) 862-867.

[4] S.D. Manjare, A.K. Ghoshal, Studies on adsorption of ethyl acetate vapor on activated carbon, Ind. Eng. Chem. Res. 45 (2006) 6563-6569.

[5] X. Zhao, Q. Ma, G.Q. Max Lu, VOC removal: comparison of MCM-41 with hydrophobic zeolites and activated carbon, Energy Fuels 12 (1998) 1051-1054.

[6] P.A. Russo, M.M.L.R. Carrott, P.J.M. Carrott, Adsorption of toluene, methylcyclohexane and neopentane on silica MCM-41. Adsorption 14 (2008) 367-375.

[7] B.L. Newalkar, N.V. Choudary, U.T. Turaga, R.P. Vijayalakshmi, P. Kumar, S. Komarneni, T.S.G. Bhat, Potential adsorbent for light hydrocarbon separation: role of SBA-15 framework porosity, Chem. Mater. 15 (2003) 1474-1479.

[8] B.L. Newalkar, N.V. Choudary, U.T. Turaga, R.P. Vijayalakshmi, P. Kumar, S. Komarneni, T.S.G. Bhat, Adsorption of light hydrocarbons on HMS type mesoporous silica, Micropor. Mesopor. Mater. 65 (2003) 267-276.

[9] F. Hoffmann, M. Cornelius, J. Morell, M. Fröba, Silica-based mesoporous organic-inorganic hybrid materials, Angew. Chem. Int. Ed. 45 (2006) 3216-3251.

[10] A. Stein, B.J. Melde, R.C. Schroden, Hybrid inorganic-organic mesoporous silicates-nanoscopic reactors coming of age, Adv. Mater 12 (2000) 1403-1419.

[11] K. Kosuge, S. Kubo, N. Kikukawa, M. Takemori, Effect of pore structure in mesoporous silicas on VOC dynamic adsorption/desorption performance, Langmuir 23 (2007) 3095-3102.

[12] H. Vinh-Thang, Q. Huang, M. Eić, D. Trong-On, S. Kaliaguine, Adsorption of $C_{7}$ hydrocarbons on biporous SBA-15 mesoporous silica, Langmuir 21 (2005) 5094-5101.

[13] C.D. Nunes, J. Pires, A.P. Carvalho, M.J. Calhorda, P. Ferreira, Synthesis and characterisation of organo-silica hydrophobic clay heterostructures for volatile organic compounds removal, Micropor. Mesopor. Mater. 111 (2008) 612-619.

[14] T.P.B. Nguyen, J. Lee, W.G. Shim, H. Moon, Synthesis of functionalized SBA-15 with ordered large pore size and its adsorption properties of BSA, Micropor. Mesopor. Mater. 110 (2008) 560-569.

[15] J. Li, L. Wang, T. Qi, Y. Zhou, C. Liu, J. Chu, Y. Zhang, Different N-containing functional groups modified mesoporous adsorbents for $\mathrm{Cr}(\mathrm{VI})$ sequestration: synthesis, characterization and comparison, Micropor. Mesopor. Mater. 110 (2008) 442-450.

[16] D. Zhao, J. Feng, Q. Huo, N. Melosh, G.H. Fredrickson, B.F. Chmelka, G.D. Stucky, Triblock copolymer syntheses of mesoporous silica with periodic 50 to 300 angstrom pores, Science 279 (1998) 548-552.

[17] E.P. Barrett, L.G. Joyner, P.P. Halenda, The determination of pore volume and area distributions in porous substances. I. Computations from nitrogen isotherms, J. Am. Chem. Soc. 73 (1951) 373-380.
[18] R. Serna-Guerrero, A. Sayari, Applications of pore-expanded mesoporous silica 7. Adsorption of volatile organic compounds, Environ. Sci. Technol. 41 (2007) 4761-4766.

[19] X.S. Zhao, G.Q. Lu, Modification of MCM-41 by surface silylation with trimethylchlorosilane and adsorption study, J. Phys. Chem. B 102 (1998) 1556-1561.

[20] Q. Wei, H. Chen, Z. Nie, Y. Hao, Y. Wang, Q. Li, J. Zou, Preparation and characterization of vinyl-functionalized mesoporous SBA-15 silica by a direct synthesis method, Mater. Lett. 61 (2007) 1469-1473.

[21] A.A. Campos, L. Dimitrov, C.R. da Silva, M. Wallau, E.A. Urquieta-González, Recrystallisation of mesoporous SBA-15 into microporous ZSM-5, Micropor Mesopor. Mater. 95 (2006) 92-103.

[22] T. Kim, F. Kleitz, B. Paul, R. Ryoo, MCM-48-like Mesoporous silicas with tailored pore structure: facile synthesis domain in a ternary triblock copolymer-butanol-water system, J. Am. Chem. Soc. 127 (2005) 7601-7610.

[23] A.S.M. Chong, X.S. Zhao, A.T. Kustedjo, S.Z. Qiao, Functionalization of large-pore mesoporous silicas with organosilanes by direct synthesis, Micropor. Mesopor. Mater. 72 (2004) 33-42.

[24] S. Yu, T.K.S. Wong, X. Hu, K. Pita, Sol-gel derived mesoporous silica films used as low dielectric constant materials, Thin Solid Films 462-463 (2004) 311-315.

[25] C. Li, J. Liu, X. Shi, J. Yang Q Yang Periodic mesoporous organosilicas with 1,4-diethylenebenzene in the mesoporous wall: synthesis, characterization, and bioadsorption properties, J. Phys. Chem. C 111 (2007) 10948-10954.

[26] X.S. Zhao, G.Q. Lu, X. Hu, Organophilicity of MCM-41 adsorbents studied by adsorption and temperature-programmed desorption, Colloids Surf. A 179 (2001) 261-269.

[27] Y.H. Yoon, J.H. Nelson, Application of gas adsorption kinetics. I. A theoretical model for respirator cartridge service life, J. Am. Ind. Hyg. Assoc. 45 (8) (1984) 509-516.

[28] C. Wu, T. Chung, T.C.K. Yang, M. Chen, Dynamic determination of the concentration of volatile alcohols in a fixed bed of zeolite 13X by FT-IR, J. Hazard. Mater. B137 (2006) 893-898.

[29] Z. Huang, F. Kang, K. Liang, J. Hao, Breakthrough of methyethylketone and benzene vapors in activated carbon fiber beds, J. Hazard. Mater. B98 (2003) 107-115.

[30] H. Zaitan, D. Bianchi, O. Achak, T. Chafik, A comparative study of the adsorption and desorption of o-xylene onto bentonite clay and alumina, J. Hazard. Mater. 153 (2008) 852-859.

[31] B.L. Newalkar, N.V. Choudary, P. Kumar, S. Komarneni, T.S.G. Bhat, Exploring the potential of mesoporous silica, SBA-15, as an adsorbent for light hydrocarbon separation, Chem. Mater. 14 (2002) 304-309. 